\title{
Pogitare
}

\section{PROTAGONISMO DE ADOLESCENTES NA CRIAÇÃO DE UM STORYBOARD PARA UM JOGO DIGITAL SOBRE HANSENÍASE}

\author{
Tamyris Arcoverde Santos ${ }^{1}$ (1) \\ Bruna de Farias Pereira de Araújo² \\ Waldemar Brandão Neto ${ }^{2}$ (1) \\ Ednaldo Cavalcante de Araújo ${ }^{1}$ (i) \\ Eliane Maria Ribeiro de Vasconcelos ${ }^{1}$ (i) \\ Estela Maria Leite Meirelles Monteiro ${ }^{1}$ (i)
}

\section{RESUMO}

Objetivo: descrever o protagonismo de adolescentes escolares na elaboração de um storyboard para um jogo digital educacional sobre hanseníase.

Método: estudo qualitativo do tipo pesquisa-ação. Realizado em uma escola pública em Pernambuco (Brasil) em 2019. Ocorreram oito oficinas pedagógicas com escolares, para conhecimento e construção do jogo digital educacional, utilizando o software Scratch versão 2.0. O processo de produção seguiu o modelo de desenvolvimento de material educativo digital, criado por Falkembach.

Resultados: a ação educativa instrumentalizou as potencialidades e estimulou a criatividade dos adolescentes para assumirem uma atitude de protagonismo na elaboração do storyboard para um jogo digital sobre hanseníase.

Conclusão: os adolescentes assumiram uma postura de protagonismo na criação do storyboard de um jogo digital sobre hanseníase. O interesse em utilizar o ambiente virtual concorreu para a desenvoltura e criatividade dos adolescentes ao serem instigados e terem acesso a condições propícias para a elaboração do storyboard.

DESCRITORES: Hanseníase; Jogos e Brinquedos; Tecnologia Educacional; Educação em Saúde; Adolescentes.

\section{PROTAGONISMO DE ADOLESCENTES EN LA CREACIÓN DE STORYBOARD PARA UN JUEGO DIGITAL SOBRE LEPRA}

\section{RESUMEN:}

Objetivo: Describir el protagonismo de escolares adolescentes en la elaboración de un storyboard para un juego digital educativo sobre lepra. Método: Estudio cualitativo, tipo investigación-acción, realizado en una escuela pública de Pernambuco (Brasil) en 2019. Se organizaron ocho talleres pedagógicos con escolares, impartiéndose conocimiento y construcción del juego digital educativo, utilizando el software Scratch versión 2.0. El proceso de producción siguió el modelo de desarrollo de material educativo digital creado por Falkembach. Resultados: La acción educativa instrumentalizó las potencialidades y estimuló la creatividad de los adolescentes, para que asumieran una actitud de protagonismo en la elaboración del storyboard para el juego digital sobre lepra. Conclusión: Los adolescentes asumieron un rol protagónico en la creación del storyboard para un juego digital sobre lepra. El interés en utilizar el ambiente virtual coadyuvó a la desenvoltura y creatividad de los adolescentes estimulados por tener acceso a condiciones propicias para elaborar el storyboard.

DESCRIPTORES: Lepra; Juegos e Implementos de Juego; Tecnología Educacional; Educación en Salud; Adolescentes. 
A hanseníase persiste como importante problema de saúde pública no Brasil, ocupando o segundo lugar como país mais endêmico do mundo, com casos notificados em todas as unidades da federação, porém com maior prevalência nas regiões Norte, Nordeste e Centro-Oeste ${ }^{(1-2)}$. O Estado de Pernambuco é o nono com maior coeficiente de detecção da hanseníase e o terceiro no Nordeste ${ }^{(3)}$.

A doença acomete principalmente a pele e os nervos das extremidades do corpo, com elevado poder incapacitante, concorrendo para aumento do absenteísmo, de restrições na vida social e problemas psicológicos desencadeados pela persistência de preconceitos e estigmas da doença(4). Dos casos novos em adultos, $24 \%$ já apresentam algum tipo de incapacidade em consequência da doença $a^{(5)}$.

A hanseníase é considerada uma enfermidade do adulto, no entanto, há elevado número de casos em menores de 15 anos, o que indica a precocidade da exposição e a persistência da transmissão da doença(6). Em 2015, foram notificados 18.230 casos em menores de 15 anos no mundo, destes, 281 apresentaram grau de incapacidade classificada com o tipo 2 no momento do diagnóstico(5).

O Estado de Pernambuco é o sexto colocado com coeficiente de detecção de casos novos em menores de 15 anos (12,14/100.000 habitantes), sendo classificado como hiperendêmico ${ }^{(5)}$, pois segundo o Ministério da Saúde (MS) se apresenta acima de 10/100.000 habitantes, mostrando assim a força da transmissão recente da endemia e sua tendência ${ }^{(7)}$.

A ocorrência da doença nos adolescentes é prejudicial não só pelos danos físicos decorrentes do diagnóstico tardio ou da não adesão ao tratamento, como também pelos danos psíquicos, desencadeados pelo estigma e isolamento social(8), em uma fase da vida marcada principalmente pelo crescimento rápido, estruturação da personalidade e integração social(9).

Em decorrência das repercussões que a hanseníase pode causar à saúde dos portadores, a Organização Mundial de Saúde (OMS) lançou, no ano 2000 com atualização quinquenal, a Estratégia Global com o propósito de abordar os desafios enfrentados no controle da doença. A Estratégia 2016-2020 alerta ser essencial o investimento em estratégias modernas de comunicação para uma conscientização sobre a hanseníase na comunidade $^{(5)}$.

As Tecnologias Educacionais (TE) vêm causando impacto positivo e têm sido cada vez mais utilizadas para facilitar o processo ensino-aprendizagem, pois são capazes de promover o diálogo e fortalecer a relação paciente-profissional. Ao abordarem assuntos relacionados à saúde, as tecnologias trazem componentes da cultura e do contexto sóciohistórico, enriquecendo a visão de mundo dos participantes, constituindo propriedades para auxiliar a autonomia dos adolescentes para tomarem decisões que promovam sua saúde ${ }^{(10)}$.

O reconhecimento da hanseníase entre as doenças negligenciadas e sua elevada ocorrência em menores de 15 anos evidencia a importância da disponibilização de TE de ampla disseminação, como ferramentas capazes de serem empregadas em políticas públicas voltadas à promoção da saúde, controle e prevenção da doença, com ênfase no ambiente escolar.

Nesse contexto, o Programa Saúde na Escola (PSE) constitui uma proposta intersetorial, que propõe uma parceria entre os profissionais da educação e a Equipe de Saúde da Família (ESF), dando ênfase no papel do enfermeiro como articulador nas ações de promoção à saúde ${ }^{(11)}$, mobilizando estratégias de educação em saúde e de acesso da 
comunidade aos serviços da atenção primária(12).

Ao agregar os pressupostos de Freire à prática educativa em saúde, emerge considerar o processo educativo como uma ferramenta progressiva, que se propõe a possibilitar processos de emancipação dos indivíduos, pelo desenvolvimento do pensar consciente sobre as questões de saúde peculiares a cada realidade social(13-14), para o controle da hanseníase. Ações de educação em saúde com grupo de escolares utilizando $\mathrm{TE}^{(15)}$ destacaram que os jogos digitais apresentaram resultados mais significativos em relação à atenção e flexibilidade cognitiva, podendo contribuir com o aprimoramento das funções executivas ${ }^{(16)}$. A proposta de elaboração da TE, neste estudo, apresenta como critério inovador o fato de não limitar o embasamento de sua construção em levantamento da literatura pertinente.

Os pressupostos teóricos metodológicos da educação crítica social de Freire(13-14) inquietaram as autoras em reconhecer e acreditar nas potencialidades e oportunizar a participação ativa dos adolescentes na construção do conhecimento, com estímulo à criatividade e ao protagonismo. Foi proposta a preparação dos adolescentes para desenvolverem um storyboard, que visa apresentar de forma simples, objetiva e de fácil entendimento uma diversidade de informações relevantes para a elaboração de um jogo digital educacional(17) para o controle e prevenção da hanseníase. Diante do exposto, o estudo tem como objetivo descrever o protagonismo de adolescentes escolares na elaboração de um storyboard um para jogo digital educacional sobre hanseníase.

\section{MÉTODO}

Estudo qualitativo do tipo pesquisa-ação, que é capaz de associar diversas formas de ação coletiva(18). A escolha do caminho metodológico retrata a intencionalidade do pesquisador diante de um determinado fenômeno(19), que neste estudo visa assegurar a realização de uma estratégia educativa centrada na participação dos adolescentes escolares.

A estratégia educativa foi realizada concomitante ao início das aulas em fevereiro até abril de 2019, em escola pública estadual em Pernambuco, Brasil. O desenvolvimento da tecnologia foi adaptado a partir do modelo de desenvolvimento de material educativo digital criado por Falkembach, que propõe uma aprendizagem construcionista, onde o aprendiz é o centro do processo de aprendizagem. Os procedimentos para desenvolver um material educativo digital devem seguir as seguintes fases: análise e planejamento, modelagem, implementação e manutenção (realizadas na primeira fase do projeto), avaliação e distribuição (desenvolvidas em um segundo momento) à validação com especialistas e públiço alvo, constituindo requisitos necessários à disponibilização do jogo digital ${ }^{(10,20-21)}$.

$\mathrm{Na}$ primeira fase, foram realizadas oito oficinas pedagógicas com seis escolares, para conhecimento e construção do jogo digital educacional, utilizando o Scratch versão 2.0, um software que utiliza de blocos lógicos, itens de som e imagem para desenvolver histórias interativas, jogos e animações. Foi escolhido por ser gratuito e ter sido projetado especialmente para desenvolvimento de jogos por indivíduos com 8 a 16 anos, além de ser utilizado nos principais sistemas operacionais (Windows, Linux e Mac).

A estratégia educativa foi realizada na biblioteca, previamente reservada, para assegurar um ambiente climatizado e tranquilo, sendo disponibilizados três computadores, um para cada dupla explorar o ambiente virtual. Cada oficina tinha a duração máxima de uma hora, agendada de modo a não comprometer as atividades curriculares do discente na escola. 
A seleção dos adolescentes ocorreu por amostragem intencional(22), obedecendo aos seguintes critérios de inclusão: adolescentes escolares regularmente matriculados, que participaram em estratégia educativa em saúde, mediadas por círculos de cultura sobre hanseníase, realizada como atividade extensionista com a participação da pesquisadora junto com graduandos de enfermagem do grupo de pesquisa, no semestre anterior. Constituiu critério de exclusão: apresentar mais de uma falta nas oficinas realizadas, fato não observado, comprovando a interação e interesse deles nas atividades de elaboração do jogo digital.

Para subsidiar o diálogo de como o conteúdo deveria ser explorado no jogo, foi utilizada a cartilha do Ministério da Saúde ${ }^{(23)}$ que aborda a hanseníase e direitos humanos. Os discursos dos adolescentes foram gravados e transcritos, para apreensão dos dados subsidiando a análise e planejamento da Tecnologia Educacional. Nesta etapa, foi construído pelos adolescentes o storyboard, que fornece a visualização gráfica das imagens das cenas, em sequência(17), estabelecendo o passo a passo do jogo. O desenvolvimento destas etapas é requisito para proceder à implementação, que corresponde à programação do jogo digital. Ela foi realizada por um profissional da área de programação.

O estudo foi aprovado pelo Comitê de Ética em Pesquisa do Centro de Ciências da Saúde da Universidade Federal de Pernambuco com o parecer $n^{\circ} 3.060 .866$.

\section{RESULTADOS}

As oficinas foram desenvolvidas com um grupo de seis adolescentes, com idade entre 13 e 18 anos, solteiros, quatro se autodeclararam pardos e dois brancos, com representação equivalente do ensino médio e fundamental, dois com curso de informática, $50 \%$ possuíam computador e o utilizavam regularmente.

A primeira oficina foi desenvolvida a partir da seguinte questão geradora: quais os conhecimentos do grupo sobre a hanseníase? O conhecimento prévio que os adolescentes possuíam por terem participado de círculos de cultura sobre a doença concorreu para que eles expressassem de forma clara e segura quais os principais conteúdos que deveriam estar presentes no jogo digital, de modo que a cartilha do Ministério da Saúde foi apenas um suporte, pois eles já haviam construído um pensamento crítico e reflexivo sobre a temática.

Na segunda oficina, a questão geradora foi: quais os requisitos necessários para a criação de tecnologia educacional digital e lúdica sobre hanseníase para adolescentes? O desenvolvimento da terceira oficina apresentou como questão geradora: quais os conhecimentos sobre a plataforma Scratch necessários para se realizar uma programação simples de um jogo digital? Esse conhecimento inicial sobre programação foi fundamental para os adolescentes escolares compreenderem o passo a passo para construção do jogo digital, e subsidiou requisitos necessários à criação do storyboard.

A quarta oficina teve como questão geradora: qual o tipo de jogo digital o grupo escolhe? Diante da impossibilidade de unir três jogos com programações diferentes, disponibilizados na plataforma, a maioria dos adolescentes optaram por um jogo baseado

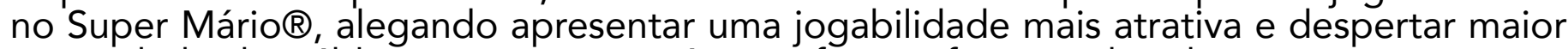
curiosidade do público. Da quinta a sétima oficinas, foi considerada a seguinte questão geradora: quais os requisitos necessários à criação do storyboard para desenvolver o jogo digital sobre hanseníase? Os adolescentes foram instigados a explorarem a criatividade para esboçar como seria abordada a temática no jogo digital e sua sequência, como também qual a sua composição e forma de apresentação dos conhecimentos relevantes.

Antecedido por momentos de pesquisa em dupla, foi proposto pelos adolescentes, 
no coletivo, que o jogo deveria apresentar questionamentos, que permitissem ao jogador realizar autoavaliação do conhecimento, com o registro dos acertos mediante aquisições de pontuação. Também destacaram a utilização de personagens e de ambientes interativos, com mobilização visual e sonora, com desafios a serem superados e oportunidades de conquista de pontuações extras, para assegurar o dinamismo do jogo. O processo de criação mediado pelo storyboard (Figura 1) foi realizado com base na exploração da desenvoltura do jogo digital, considerando as expectativas e desejos dos adolescentes. $O$ Quadro 1 representa os requisitos, objetivos e especificações utilizadas pelos adolescentes na criação do storyboard.

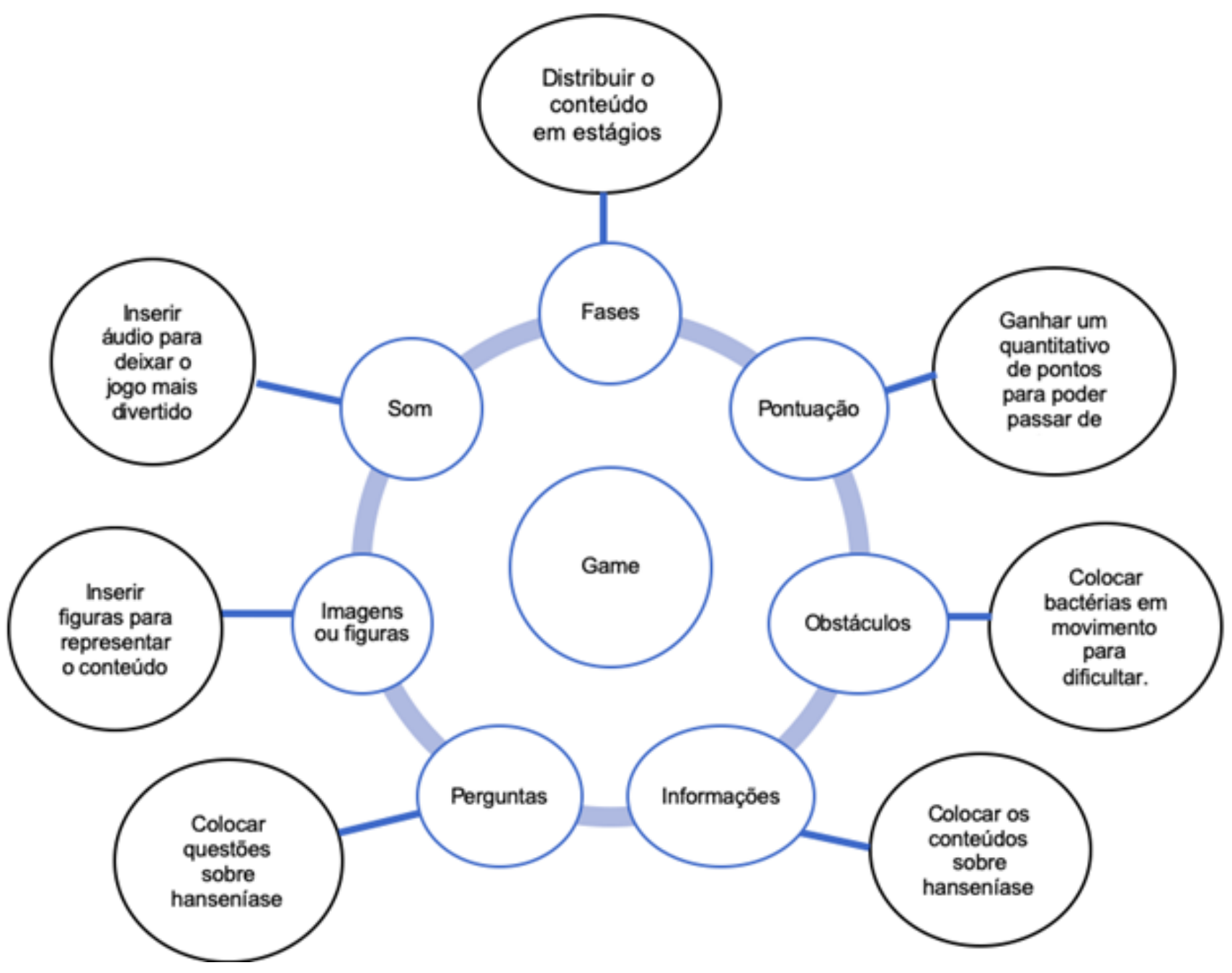

Figura 1 - Storyboard desenvolvido pelos adolescentes. Recife, PE, Brasil, 2019

Fonte: Autores, 2019.

Quadro 1 - Protagonismo dos adolescentes na criação do storyboard para o jogo digital "Game Hanse". Recife, PE, Brasil, 2019 (continua)

\begin{tabular}{|l|l|l|}
\hline REQUISITOS & OBJETIVOS & ESPECIFICAÇÕES \\
\hline $\begin{array}{l}\text { Distribuição do } \\
\text { conteúdo em estágios }\end{array}$ & $\begin{array}{l}\text { Apresentar uma ordenação } \\
\text { crescente dos conteúdos } \\
\text { abordados }\end{array}$ & $\begin{array}{l}\text { Os adolescentes elaboraram quatro estágios: } \\
\text { 1. conceito e epidemiologia; 2. transmissão; } \\
\text { 3. sinais e sintomas; 4. tratamento e } \\
\text { discriminação }\end{array}$ \\
\hline
\end{tabular}




\begin{tabular}{|l|l|l|}
\hline $\begin{array}{l}\text { Informações e } \\
\text { questionamentos }\end{array}$ & $\begin{array}{l}\text { Investigar se o jogador está } \\
\text { atento e consegue apreender os } \\
\text { conteúdos abordados no jogo }\end{array}$ & $\begin{array}{l}\text { Os adolescentes criaram nove perguntas } \\
\text { sobre a temática para contribuir na } \\
\text { problematização da temática no jogo }\end{array}$ \\
\hline $\begin{array}{l}\text { Cenários, Imagens ou } \\
\text { Figuras }\end{array}$ & $\begin{array}{l}\text { Ilustrar o conteúdo de modo } \\
\text { a contribuir para a clareza e } \\
\text { apreensão da mensagem }\end{array}$ & $\begin{array}{l}\text { Os adolescentes descreveram que imagens } \\
\text { ou figuras seriam mais apropriadas para } \\
\text { apreensão do conteúdo }\end{array}$ \\
\hline Áudio & Deixar o jogo mais divertido & $\begin{array}{l}\text { Os adolescentes optaram em colocar o som } \\
\text { do jogo Super Mario, considerando torná-lo } \\
\text { mais atrativo }\end{array}$ \\
\hline Obstáculos & $\begin{array}{l}\text { Estabelecer obstáculos para } \\
\text { desafiar o jogador }\end{array}$ & $\begin{array}{l}\text { Os adolescentes destacaram o interesse pelo } \\
\text { desafio de um jogo, propondo a presença de } \\
\text { uma bactéria em movimento para desafiar o } \\
\text { jogador, associando aos desafios requeridos } \\
\text { para o controle da doença }\end{array}$ \\
\hline $\begin{array}{l}\text { Pontuação e mudança } \\
\text { de estágio }\end{array}$ & $\begin{array}{l}\text { Estimular o jogador a aumentar } \\
\text { sua pontuação com a obtenção } \\
\text { de respostas corretas aos } \\
\text { questionamentos }\end{array}$ & $\begin{array}{l}\text { Os adolescentes estabeleceram cinco pontos } \\
\text { para cada resposta correta e menos dois para } \\
\text { resposta errada }\end{array}$ \\
\hline
\end{tabular}

Fonte: Autores, 2019.

Na oitava oficina, com o jogo digital já programado, a questão geradora foi: como os adolescentes avaliaram os estágios propostos no storyboard? Na oficina final, os adolescentes foram estimulados a tecerem uma apreciação da produção coletiva proposta para o jogo digital, como também a sugerirem modificações que julgassem essenciais. $O$ nome escolhido pelos adolescentes para a Tecnologia Educacional foi "Game Hanse".

O objetivo do jogo digital educacional é disponibilizar acesso a conhecimentos sobre hanseníase, para adolescentes, de maneira lúdica, interativa e participativa. Os conteúdos apresentados foram: conceito, epidemiologia, transmissão, sinais e sintomas, tratamento e estigma. O avatar, personagem central do jogo, foi representado por um adolescente, finalizando a primeira versão do "Game Hanse" proposto por adolescentes, a ser submetido ao processo de validação.

\section{DISCUSSÃO}

O quadro epidemiológico da hanseníase no contexto brasileiro e a ocorrência da hiperendemicidade entre menores de 15 anos demandam estudos para auxiliar políticas públicas de enfrentamento e promoção da saúde, junto a esse grupo etário, no controle da doença. Estudos evidenciam que investir na saúde dos adolescentes constrói uma intervenção importante não só para esta etapa do ciclo de vida, como também para as gerações futuras ${ }^{(24-25)}$.

O enfermeiro, como membro articulador da equipe nas ações de promoção à saúde, vem destacar o papel de educador em saúde, em todos os níveis de assistência, mas principalmente na atenção primária ${ }^{(12,15)}$. $O$ envolvimento da população adolescente requer deste profissional estratégias de mobilização e negociação para estabelecer uma parceria com gestores, coordenadores e professores, no desenvolvimento de ações interdisciplinares em educação em saúde no cenário escolar.

O presente estudo segue uma proposta que se contrapõe à abordagem tradicional 
do ensino, embasada em relações educacionais verticalizadas, denominada de educação bancária. O ensino crítico social, proposto por Freire, fundamentou a necessidade de estabelecer estratégias de participação dos educandos na construção do conhecimento(13-14), além de estimular o desenvolvimento de uma responsabilização social, ao contribuir com a produção de ferramenta tecnológica capaz de auxiliar os profissionais no desenvolvimento das ações de educação em saúde sobre hanseníase.

A criação do storyboard para o "Game Hanse" foi desenvolvida com a participação de adolescentes escolares de escola pública, para compartilhar conhecimentos sobre hanseníase de forma lúdica e prazerosa. A elaboração do jogo digital educacional instigou a postura de protagonismo dos adolescentes, a partir do reconhecimento e valorização dos seus conhecimentos sobre a hanseníase, mediante participação anterior em projeto de extensão com desenvolvimento de círculos de cultura ${ }^{(26)}$ sobre a temática. Assim, os participantes apresentavam conhecimentos prévios e identificação com abordagens ativas de ensino.

A etapa inicial, denominada de análise e planejamento(20) ${ }^{(20}$ ara elaboração do jogo digital, neste estudo delimitou a criação do storyboard pelos adolescentes, escolhida por seu caráter didático, delineando de modo sistemático as atividades a serem executadas em cada fase.

O jogo digital como tecnologia educacional constitui-se de um recurso lúdico, que confere descontração, interatividade e possível ação educativa, considerando sua aceitação e utilização cada vez mais presente no cotidiano dos adolescentes ${ }^{(10)}$. $\mathrm{O}$ estudo explora e destaca o potencial dos adolescentes em atuarem como protagonistas no desenvolvimento de tecnologia educacional para melhorar a eficiência na disseminação de conhecimento em saúde para a população, com ênfase no período da adolescência.

No entanto, é requerida a superação de práticas e modelos fragmentados e pontuais de educação em saúde, caracterizados por uma postura de submissão e passividade de indivíduos e grupos sociais ${ }^{(13-14)}$. Os sistemas de saúde devem promover condições propícias ao exercício da responsabilidade social, assegurando aos adolescentes atuarem na elaboração e utilização dos recursos digitais ${ }^{(24)}$.

A abordagem de ensino crítico social ${ }^{(13-14)}$ fomentou o processo ensino-aprendizagem na realização das oficinas de elaboração de jogos digitais (games educacionais) que proporcionassem uma ambiência dialógica entre educandos e educadores, promotora da troca de conhecimentos, com estímulo às inquietações e ao desenvolvimento de processos criativos pelos participantes ${ }^{(10)}$.

A realização das oficinas assegurou o respeito à autonomia, aos saberes e vivências dos adolescentes no processo de ensino-aprendizagem, contribuindo para uma perspectiva cooperativa com o educador e os demais colegas, no entrelace entre os saberes populares e científicos para o desenvolvimento do jogo digital(10).

As oficinas constituíram arenas dialéticas de ensino, a partir de inquietações, buscas, tentativas, erros e acertos, até uma nova concepção propositiva do coletivo ${ }^{(13-14)}$. A pesquisadora foi desafiada a assumir uma ação educadora inovadora e comprometida com o respeito à autonomia dos participantes, ao reconhecer um contexto de ensino público descontextualizado dos avanços tecnológicos e propor o acesso ao ambiente virtual como proposta de construção do conhecimento.

Durante as oficinas, o grupo identificou lacunas no conhecimento entre os pares sobre hanseníase, elencando os principais pontos a serem abordados e as características peculiares ao jogo digital que despertariam maior interesse dos jogadores. No desenvolvimento das oficinas sobre jogos, observou-se o interesse e a motivação dos adolescentes pelo processo de criação e programação em ambiente virtual.

A elaboração de jogo digital educacional em saúde vem sendo desenvolvida 
em estudos científicos, com objetivo de disseminação de conhecimento por meio de atividades lúdicas, que aproximam o adolescente à exploração do ambiente virtual para seu autocuidado. Entretanto, alguns estudos são centrados no pesquisador ou no máximo em conhecimentos apreendidos junto ao grupo populacional a que se destina a tecnologia educacional(10,15). Emerge destacar o efeito positivo do jogo digital educacional que explorou os cuidados em saúde para pacientes adolescentes com câncer, como uma ferramenta para aprender sobre a doença e o autocuidado durante o tratamento(27).

Programa de aprendizagem baseado em jogos facilita a experiência de aprendizagem consciente e criativa. Os jogos disponibilizam alguns mecanismos adicionais de aprimoramento: compartilhamento de ideias, questionamentos e tarefas, componentes de design, feedback imediato e recompensas por desempenho de alta qualidade ${ }^{(27)}$.

O estudo dialoga com a Estratégia Global para Hanseníase (2016-2020), que recomenda uma aceleração rumo ao mundo sem hanseníase, tendo por objetivo reduzir a carga global e local da hanseníase, reforçando a conscientização da comunidade, promovendo a detecção precoce e assegurando o início imediato ao tratamento ${ }^{(3)}$, medidas que requerem o acesso da população a conhecimento sobre a doença.

O planejamento do jogo digital educacional explorou em seu conteúdo questões relevantes como: identificação do agente etiológico, forma de transmissão, sinais e sintomas, diagnóstico, tratamento, prevenção, cura e enfretamento do estigma, contemplando as sugestões dos adolescentes, com atenção para evitar o uso de termos técnicos e empregar uma linguagem acessível|(3).

A participação dos adolescentes consolidou a definição do personagem central e demais personagens e estruturas interativas do jogo digital, a escolha do tipo de jogo e de sua forma de apresentação. Assim, durante o processo criativo, expectativas foram consolidadas e concomitantemente geradas novas inquietações e expectativas, envolvendo e motivando o exercício do protagonismo.

$\mathrm{Na}$ elaboração do storyboard para um jogo digital, destaca-se a composição da comunicação escrita em associação com a comunicaçãovisual, comasfiguras dospersonagens e imagens que retratam os cenários no ambiente virtual (17). A utilização de recursos visuais contribui para a comunicação de ideias científicas relevantes para os cuidados em saúde, ao considerar que a imagem se destaca pelo fato de ser autoexplicativa, possibilitando transpor a barreira da linguagem e agregar informações aos textos propostos ${ }^{(21)}$.

Compete ao enfermeiro escolar (atuante em alguns países) apresentar habilidades nos vários métodos de comunicação com os adolescentes, para estabelecer programa de saúde escolar eficaz ${ }^{(28)}$, como também desenvolver um aprimoramento no uso da tecnologia digital para comunicação com a população adolescente ${ }^{(29)}$.

A abordagem do conteúdo sobre prevenção, adesão ao tratamento e enfretamento do estigma da hanseníase foi modificada quanto à linguagem, tornando o texto mais claro. $O$ jogo digital proposto pelos adolescentes apresenta uma associação entre textos e imagens, ampliando a exploração de diferentes sensações, devido à força e diversidade de comunicação que elas representam no desenvolvimento e potencialização do processo educativo ${ }^{(21)}$.

Ao pensar no contexto atual, marcado por constantes mudanças provocadas por inovações tecnológicas, utilizar um jogo digital educacional validado no ambiente de sala de aula ou em serviços de saúde subsidia agregar esta tecnologia nas estratégias educacionais em saúde, favorecendo situações de aprendizagem agradável e proveitosa ${ }^{(14-15)}$.

A tecnologia é uma extensão do nosso cérebro, uma maneira diferente de pensar, um instrumento para lidar em diversos contextos ${ }^{(28)}$. Estudo de ensaio clínico controlado randomizado, de método misto, desenvolvido nos Estado Unidos da América, com aplicação de um jogo digital entre estudantes do ensino médio para explorar o potencial do jogo 
virtual em atividades sociais, emocionais e desenvolvimento cognitivo na promoção do pensamento ético e considerações morais para tomada de decisão, verificou que os que participaram das discussões depois de jogar, apresentaram resposta mais complexas ${ }^{(29)}$.

As novas tecnologias precisam ser incorporadas à pedagogia, estimulando a inteligência com o desenvolvimento de conhecimentos, considerando as potencialidades disponibilizadas pelo ambiente virtual de aprendizagem. A escola constitui um cenário valorativo no estabelecimento de ações compartilhadas em saúde e formação cidadã da população adolescente.

Professores de escolas primárias na Espanha perceberam um aumento na frequência do uso de aplicativos em sala de aula, destacando a importância desse recurso para o acesso imediato a informações significativas sobre o impacto da aprendizagem ${ }^{(30)}$. Neste cenário, emerge a importấncia da atuação do enfermeiro em parceria com os demais profissionais da saúde e educação, no desenvolvimento de estratégias promotoras da saúde deste grupo populacional com ênfase no controle e prevenção da hanseníase.

Quanto às limitações, durante a execução das oficinas, houve dificuldades para disponibilização de equipamentos tecnológicos e inflexibilidade de horário dos participantes.

\section{CONSIDERAÇÕES FINAIS}

O desenvolvimento da etapa de criação do "Game Hanse" pelos adolescentes constituiu o diferencial deste estudo, ao propiciar o exercício do protagonismo no desenvolvimento sistemático e criativo de etapas articuladas e processuais. O protagonismo do grupo na elaboração do storyboard para um jogo digital valorizou as características do público-alvo, construindo um jogo virtual com uma identidade própria.

A experiência da pesquisadora com a realização das oficinas de capacitação dos adolescentes, no desenvolvimento de jogos digitais, propiciou uma ampliação na construção do conhecimento sobre a utilização de metodologias ativas, com abordagem de ensino crítica social na elaboração participativa do storyboard, fomentando o reconhecimento das potencialidades dos adolescentes como agentes de transformação na realidade de saúde. Ao considerar e estimular o seu protagonismo e os avanços nas propostas educacionais com o desenvolvimento tecnológico como ferramenta na construção de conhecimentos sobre hanseníase e direitos de cidadania.

O "Game Hanse" vem consolidar uma perspectiva de agregar nos estudos de produção de tecnologia educacional o envolvimento e participação do público-alvo. Emerge o papel de educador em saúde, como responsabilidade do enfermeiro e demais profissionais, que necessitam ter acesso a tecnologias educacionais para a inclusão do público adolescente nas ações de promoção a saúde e enfrentamento da hanseníase como problema de saúde pública.

\section{REFERÊNCIAS}

1. Ministério da Saúde (BR). Secretaria de Vigilância em Saúde. Boletim Epidemiológico: hanseníase.

[Internet]. Brasília: Ministério da Saúde; 2018 [acesso em 02 fev 2019]. Disponível em: https://www.saude. gov.br/images/pdf/2018/janeiro/31/2018-004-Hanseniase-publicacao.pdf. 
2. Souza ACC de, Moreira TMM, Borges JWP. Educational technologies designed to promote cardiovascular health in adults: integrative review. Rev. esc. enferm. USP [Internet]. 2014 [acesso em 06 abr 2019]; 48(5). Disponível em: http://dx.doi.org/10.1590/S0080-6234201400005000023.

3. World Health Organization (WHO). Global Leprosy Strategy 2016-2020. Accelerating towards a leprosy-free world. Monitoring and Evolution Guide. Geneva: WHO; 2017.

4. Faria CRS de, Fregonesi CEPT, Corazza DAG, Andrade DM de, Mantovani NADT, Silva JR, et al. Grau de incapacidade física de portadores de hanseníase: estudo de coorte retrospectivo. Arq. Ciênc. saúde. [Internet]. 2015 [acesso em 07 abr 2019]; 22(4). Disponível em: https://doi.org/10.17696/23183691.22.4.2015.122.

5. World Health Organization (WHO). Global leprosy update, 2016: accelerating reduction of disease burden. Bull Epidemiol Hebd, Geneva, WHO, n. 35, sept. 2017.

6. Luna ICF, Moura LTR de, Vieira MCA. Clinical epidemiological profile of Leprosy in children under 15 years in the city of Juazeiro-BA. Rev Bras Promoc Saúde [Internet]. 2014. [acesso em 10 mar 2019]; 26(2). Disponível em: https://www.researchgate.net/publication/307844141 Clinical epidemiological profile of leprosy in children under 15 years in the city of Juazeiro-BA.

7. Ministério da Saúde (BR). Registro ativo: número e percentual, casos novos de hanseníase: número, taxa e percentual, faixa etária, classificação operacional, sexo, grau de incapacidade, contatos examinados, por estados e regiões. [Internet]. Brasília: Ministério da saúde; 2016. [acesso em 12 dez 2018]. Disponível em: https://www.saude.gov.br/images/pdf/2019/julho/17/Registro-ativo-n--mero-epercentual--Casos-novos-de-hansen--ase-n--mero--coeficiente-e-percentual--faixa-et--ria--classifica----ooperacional--sexo--grau-de-incapacidade--contatos-examinados--por-UF-regi--es-Br-2018.pdf.

8. Silveira MGB, Coelho AR, Rodrigues SM, Soares MM, Camillo GN. Portador de Hanseníase: impacto psicológico do diagnóstico. Psicol. Soc. [Internet]. 2014. [acesso em 12 mar 2019]; 26(2). Disponível em: https://dx.doi.org/10.1590/S0102-71822014000200027.

9. Vinagre $M$ da G, Barros L. Preferências dos adolescentes sobre os cuidados de saúde. Ciênc. saúde coletiva [Internet]. 2019 [acesso em 02 ago 2020]; 24(5). Disponível em: http://dx.doi.org/10.1590/1413$\underline{81232018245.04362019 .}$

10. Serafim ARR de M, Silva ANS, Alcântara CM de, Queiroz MVO. Construção de serious games para adolescentes com diabetes mellitus tipo 1. Acta paul. enferm. [Internet]. 2019 [acesso em 02 ago 2020]; 32(4). Disponível em: https://doi.org/10.1590/1982-0194201900052.

11. Farias ICV de, Sá RMPF de, Figueiredo N, Menezes Filho A. Análise da intersetorialidade no Programa Saúde na Escola. Rev. Bras. Educ. Méd. [Internet]. 2016 [acesso em 14 abr 2019]; 40(2). Disponível em: https://dx.doi.org/10.1590/1981-52712015v40n2e02642014.

12. Maria DS, Guilamo-Ramos V, Jemmott LS, Derouin A, Villaruel A. Nurses on the Front lines: improving adolescent sexual and reproductive health across health care settings. Am J Nursing. [Internet]. 2017 [acesso em 20 abr 2019]; 117(1). Disponível em: https://dx.doi.org/10.1097/01. NAJ.0000511566.12446.45.

13. Freire P. Educação como prática da liberdade. 34. ed. São Paulo: Paz e Terra; 2011.

14. Freire P. Pedagogia do oprimido Rio de Janeiro: Paz e Terra; 2015.

15. Mariano MR, Rebouças CB de A, Pagliuca LMF. Educative game on drugs for blind individuals: development and assessment. Rev Esc Enferm USP. [Internet]. 2013. [acesso em 20 abr 2019]; 47(4). Disponível em: https://doi.org/10.1590/S0080-623420130000400022.

16. Ramos DK, Segundo FR. Jogos digitais na escola: aprimorando a atenção e a flexibilidade cognitiva. Educ. Real. [Internet]. 2018 [acesso em 21 abr 2019]; 43(2). Disponível em: https://doi.org/10.1590/2175623665738.

17. Pinto T da RC, Castro DS de, Bringuente ME de O, Sant' Anna HC, Souza TV, Primo CC. Educational 
animation about home care with premature newborn infants. Rev bras enferm [Internet]. 2018 [acesso em 25 mar 2019]; 71(Supl.4). Disponível em: http://dx.doi.org/10.1590/0034-7167-2017-0401.

18. Thiollent M. Metodologia da pesquisa-ação. 16. ed. São Paulo: Cortez; 2008.

19. Minayo MCS. O desafio do conhecimento: pesquisa qualitativa em saúde. 13. ed., São Paulo: Hucitec; 2013.

20. Falkembach GAM. Concepção e desenvolvimento de material educativo digital. Revista Novas Tecnologias na Educação - CINTED - Centro Interdisciplinar de Novas Tecnologias na Educação; 2005.

21. D'Avila CG, Puggina AC, Fernandes RAQ. Construction and validation of an educational game for pregnant women. Esc. Anna Nery [Internet]. 2018. [acesso em 20 abr 2019]; 22(3). Disponível em: https:// doi.org/10.1590/2177-9465-ean-2017-0300.

22. Polit DF, Beck CT. Fundamentos de pesquisa em enfermagem: métodos, avaliação e utilização. 7. ed. Porto Alegre: Artmed; 2011.

23. Ministério da Saúde (BR). Secretaria de Vigilância em Saúde. Departamento de Vigilância Epidemiológica. Como ajudar no controle da hanseníase? [Internet]. Brasília: Ministério da Saúde, 2008. [acesso em 02 fev 2019]. Disponível em: http://bvsms.saude.gov.br/bvs/publicacoes/como ajudar controle hanseniase.pdf.

24. Dick B, Ferguson BJ. Health for the world's adolescents: a second chance in the second decade. J Adolesc Health. [Internet]. 2015 [acesso em 21 abr 2019]; 56(1). Disponível em: https://doi.org/10.1016/j. jadohealth.2014.10.260.

25. Patton GC, Sawyer SM, Santelli JS, Ross DA, Afifi R, Allen NB, et al. Our future: a lancet commission on adolescent health and wellbeing. The lancet [Internet]. 2016 [acesso em 21 abr 2019]; 387(10036). Disponível em: https://doi.org/10.1016/S0140-6736(16)00579-1.

26. Monteiro EMLM, Vieira NFC. Educação em saúde a partir de círculos de cultura. Rev. bras. enferm. [Internet]. 2010 [acesso em 06 ago 2020]; 63(3). Disponível em: https://doi.org/10.1590/S003471672010000300008.

27. Kato PM, Beale IL. Factors affecting acceptability to young cancer patients of a psychoeducational video game about cancer. J. pediatr Oncology Nurs. [Internet]. 2006 [acesso em 19 abr 2019]; 23(5). Disponível em: https://doi.org/10.1177/1043454206289780.

28. Searing LM, Molly G. Characteristics of Ilinois School Districts that Employ School Nurses. J School Nursing [Internet]. 2016 [acesso em 21 abr 2019]; 32. Disponível em: https://doi. org/10.1177/1059840515608921.

29. Salau OR, Ogunfowokan AA. Pubertal Communication Between School Nurses and Adolescent Girls in Ile-Ife, Nigeria. J School Nursing [Internet]. 2019 [acesso em 19 abr 2019]. Disponível em: https://doi. org/10.1177/1059840517727831.

30. Domingo MG, Garganté $A B$. Exploring the use of educational technology in primary education: Teachers' perception of mobile technology learning impacts and applications use in the classroom. Computt Hum Behav [Internet]. 2016 [acesso em 22 abr 2019]; 56. Disponível em: https://doi. org/10.1016/j.chb.2015.11.023. 
COMO REFERENCIAR ESTE ARTIGO:

Santos TA, Araújo B de FP de, Brandão Neto W, Araújo EV de, Vasconcelos EMR de, Monteiro EMLM. Protagonismo de adolescentes na criação de um storyboard para um jogo digital sobre hanseníase. Cogitare enferm. [Internet]. 2021 [acesso em "colocar data de acesso, dia, mês abreviado e ano"]; 26. Disponível em: http://dx.doi.org/10.5380/ce.v26i0.71478.

*Artigo extraído da dissertação de mestrado "Game educacional sobre hanseníase: uma construção embasada no protagonismo de adolescentes escolares". Universidade de Pernambuco, 2019.

Recebido em: 03/02/2020

Aprovado em: 14/08/2020

Editora associada: Tatiane Herreira Trigueiro

Autor Correspondente:

Tamyris Arcoverde Santos

Universidade Federal de Pernambuco - Recife, PE, Brasil

E-mail: tamynha18@hotmail.com

Contribuição dos autores:

Contribuições substanciais para a concepção ou desenho do estudo; ou a aquisição, análise ou interpretação de dados do estudo - BFPA

Aprovação da versão final do estudo a ser publicado - WBN, ECA, EMRV

Responsável por todos os aspectos do estudo, assegurando as questões de precisão ou integridade de qualquer parte do estudo - TAS, EMLMM

Copyright (c) 2021 Este é um artigo em acesso aberto distribuído nos termos da Licença Creative Commons Atribuição, que permite o uso irrestrito, a distribuição e reprodução em qualquer meio desde que o artigo original seja devidamente citado. 